\title{
PAPILLIFEROUS TUMOURS OF THE HEART VALVES
}

\author{
BY \\ D. HEATH, P. V. BEST, ${ }^{*}$ and B. T. DAVIS \\ From the Department of Pathology, The University of Birmingham
}

Received March 21, 1960

After the first year of life the valves of the human heart become covered by filiform tags, known as Lambl's excrescences. These have been shown by Magarey (1949) to be the result of the organization of partially attached deposits of fibrin on the surface of the valve, and hence may be regarded as a normal ageing process. Lambl's excrescences rarely exceed $1 \mathrm{~cm}$. in length and produce no pathological sequelæ.

Exceptionally, much larger polyps occur on the cardiac valves in the form of papilliferous tumours. Even these usually occur in otherwise normal hearts and rarely give rise to symptoms. Bohrod (1929) for instance described them as "small, harmless bodies". However, the present report of two further examples of such papilliferous tumours of the heart valves shows that, if they arise near the origin of a coronary artery, they may cause symptoms.

Case 1. A man, aged 57 years, died from generalized peritonitis following a total gastrectomy for an adenocarcinoma of the stomach. At autopsy the heart weighed $310 \mathrm{~g}$. The cardiac chambers were normal in size. The thickness of the right ventricle was $3 \mathrm{~mm}$. and that of the left ventricle was $13 \mathrm{~mm}$. The tricuspid, mitral, and aortic valves were normal in structure. Two of the three cusps of the pulmonary valve were partially fused. There was no evidence of previous bacterial endocarditis and the fusion appeared to be congenital in nature. On the ventricular surface of the normal cusp was a soft, papilliferous polyp, $5 \mathrm{~mm}$. in diameter. There was only one coronary artery; this originated from the left coronary sinus.

On histological examination the polyp had a papillary structure (Fig. 1). The villi were covered with flattened endothelium-like cells (Fig. 2). The core of each villus was composed of hyaline fibrous tissue in which few cells and no blood vessels could be seen (Fig. 2). Between this fibrous core and the lining endothelium there was a layer of fibrillar myxomatous tissue which was basophilic on staining with hæmatoxylin and eosin (Fig. 2). Rounded cells, resembling macrophages, with eccentric nuclei and vacuolated cytoplasm were found in this loose tissue. The mucinous material of the myxomatous zone and the macrophages stained feebly with the periodic acid-Schiff reagents, indicating the presence of carbohydrate. This substance proved to be a mucin, as it gave a positive reaction with Southgate's mucicarmine. More precisely it appeared to consist of acid mucopolysaccharide, for it stained strongly with Hale's dialysed iron, the strength of the reaction overshadowing the lack of specificity generally associated with it. Metachromasia was demonstrated with toluidine blue. Small irregular clumped masses of tissue staining positively with Verhoeff's stain for elastic tissue were seen in the pedicle, but not in the tumour villi. Iron pigment was absent.

Case 2. A woman, aged 45 years, had occasional attacks of severe anginal pain over a period of several years. The pain was felt in the left arm and chest. It was not brought on by physical effort and passed off very rapidly. She died following accidental coal-gas poisoning. The heart was small, weighing $250 \mathrm{~g}$. The thickness of the right ventricle was $3 \mathrm{~mm}$. and that of the left ventricle was $10 \mathrm{~mm}$. The tricuspid, pulmonary, and mitral valves were normal in structure, the circumferences of the tricuspid and mitral valves being $9.5 \mathrm{~cm}$. and $7.0 \mathrm{~cm}$. respectively. The circumference of the aortic valve was $5.8 \mathrm{~cm}$. On the anterior cusp of the aortic valve, $3 \mathrm{~mm}$. to the left of the central nodule, was a pedunculated polyp (Fig. 3). The stalk was $3 \mathrm{~mm}$. long and $2 \times 1 \mathrm{~mm}$. in cross-section. There was a villous nodule on the end of this which measured $8 \times 7 \times 5 \mathrm{~mm}$. This tumour resembled a sea anemone in appearance and at autopsy was found to be capable of falling back into the anterior aortic sinus to block partially the origin of the right coronary artery (Fig. 3). The ascending aorta showed fatty streaking of the intima and there was no organic narrowing of the coronary ostia, which appeared normal. The coronary arteries also showed

* Present address, Department of Pathology, University of Aberdeen. 


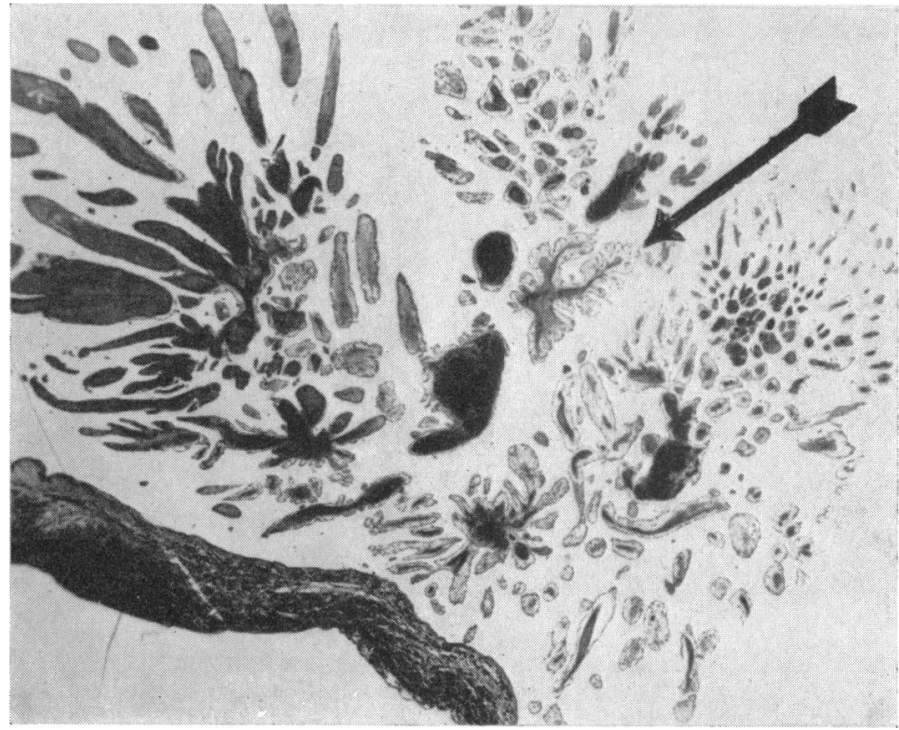

Fig. 1. Case 1.-A section through the pulmonary valve and the tumour growing from it. The tumour is highly papilliferous. The frond of the tumour indicated by a black arrow is illustrated at higher magnification in Fig. 2. Stain, hæmatoxylin and eosin $(\times 16)$ photographed with filter to increase contrast.

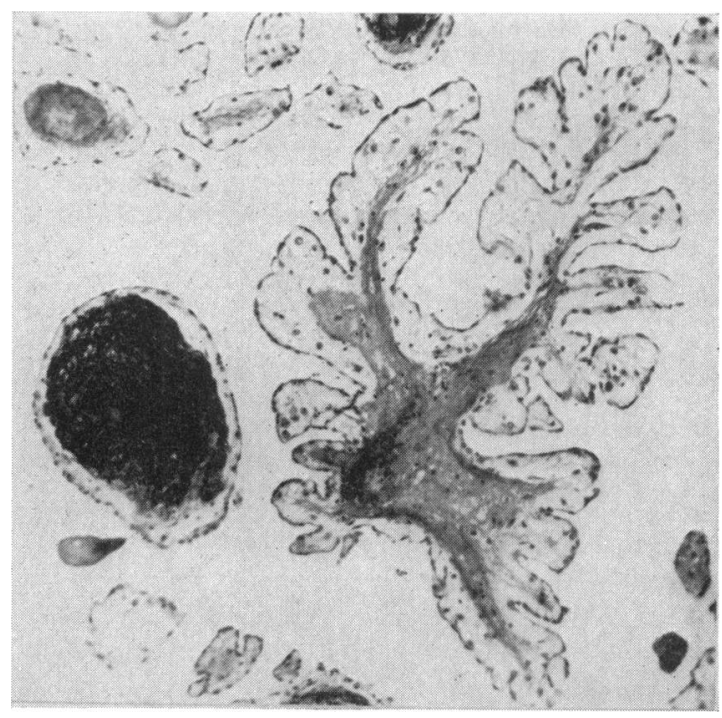

Fig. 2.-Case 1.-A section through one of the fronds of the tumour indicated in Fig. 1 by a black arrow. It is covered with flattened endothelium-like cells. The core consists of fibrous tissue. Between the two is a layer of myxomatous tissue, the staining properties of which are described in the text. To the left of the photograph part of the pedicle is seen in transverse section. Stain, hæmatoxylin and eosin $(\times 75)$. 

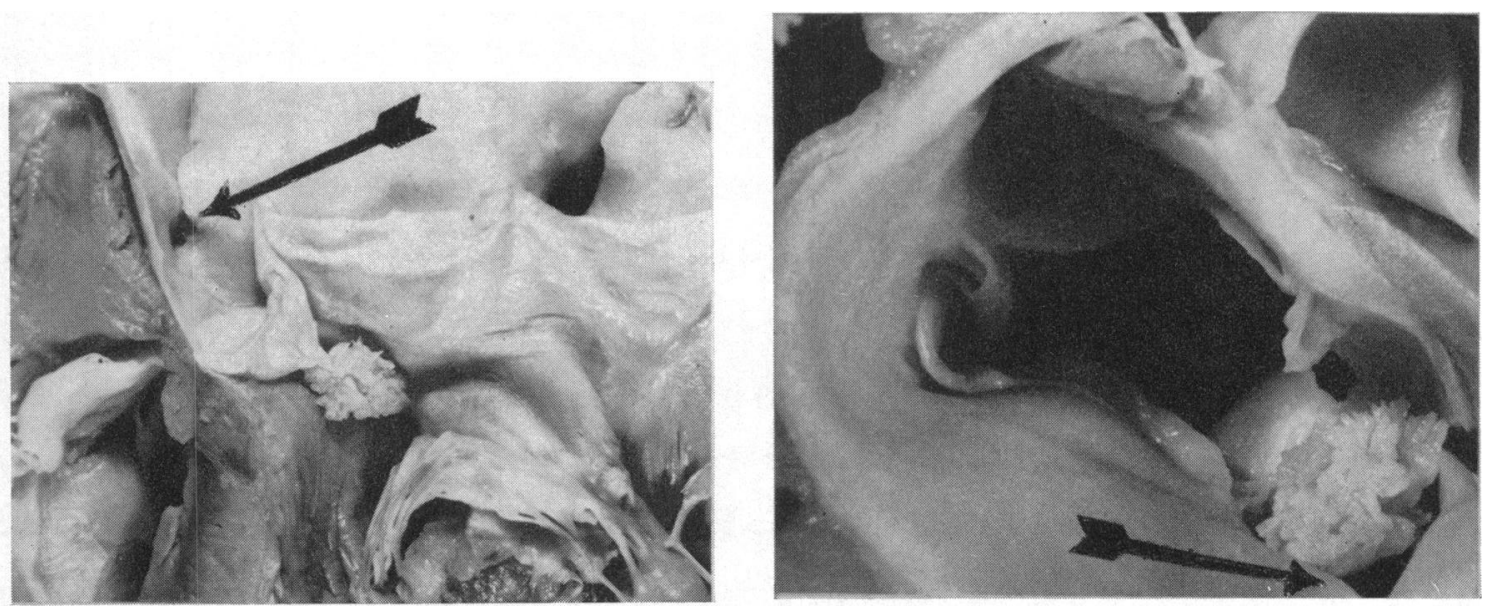

FIG. 3.-Case 2.-On left: The left ventricle has been opened to show the aortic valve and the anterior cusp of the mitral valve. A papiliferous tumour is seen attached to the anterior cusp of the aortic valve. The ostium of the right coronary artery is indicated by a black arrow. The ostium of the left coronary artery is also seen; the aorta was dissected to display this vessel and later partially reconstituted, so that the ostium has the spurious appearance of being widely dilated. On right: The aorta has been cut across to show the aortic valve from above and the position of the tumour in life. The papilliferous growth, which looks like a sea-anemone, arises from the anterior cusp and fills the anterior aortic sinus. The position of the ostium of the right coronary artery is indicated by a black arrow. This photograph demonstrates how the tumour could impede the coronary blood flow during life.

but minimal atherosclerosis, without narrowing of any of the main branches. The cusps of the aortic valve were free from atheroma.

On histological examination the tumour was papilliferous, but the individual villi were less delicate than in Case 1 (Fig. 5). Each villus consisted of a central core of collagen, surrounded in places by myxomatous material and lined by endothelium, but the myxomatous zone was much smaller than in the previous case (Fig. 5). The cellular lining differed from that of the previous case in that many of the cells were plump and distended with an acid mucopolysaccharide, which gave the same reactions as those described in Case 1.

Cellular polyps composed of a single cell hanging from the surface of the tumour were seen. Other cells were found deeper in the tumour. In this situation the mucopolysaccharide formed a densely-staining ring at the periphery of the enclosed cell which often appeared shrunken with an eccentric nucleus (Fig. 4). The cytoplasm of these cells was packed with PAS-positive granules. Some of the deeply embedded cells had no nucleus and a granular cytoplasm so that they resembled corpora amylacea. Some of the viable cells which contained mucopolysaccharide were multinucleate.

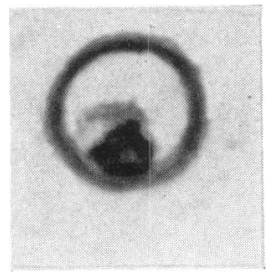

FIG. 4.-Case 2.-Cell found within the tumour. A broad ring of strongly positive PAS-positive material surrounds the cell which is shrunken, probably an artifact due to histological technique. The cytoplasm of the cell contains much PASpositive material. The nucleus is irregular. Stain, periodic-acid-Schiff $(\times 1270)$.

In the centres of many of the cores of fibrous tissue there was much granular material, which stained yellow with Van Gieson's stain. This material, together with some in a narrow zone immediately beneath the endothelium, readily took up Verhoeff's stain for elastic tissue (Fig. 5). Although this material was particulate rather than fibrillar, the form usually associated with elastic tissue, there seems little doubt that it was elastin. Probably the particulate form of the elastic tissue was a result of the repeated trauma to the tumour by the flow of blood through the aortic valve. The pedicle of the tumour also consisted of fibroelastic tissue. No iron pigment was found in the tumour. Metachromasia with toluidine blue was seen in the pedicle and myxomatous zone. 


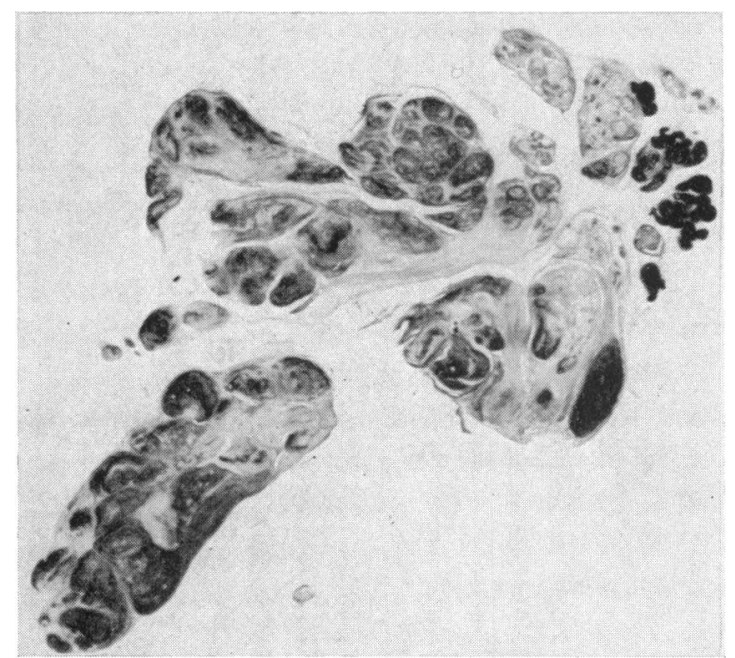

Fig. 5.-Case 2.-A section through the tumour growing from the aortic valve, which is illustrated in Fig. 3 . The villi of the tumour are much less finely papilliferous and there is less myxomatous material than in Case 1. They consist largely of fibrous tissue and elastic tissue. Stain, elastic/Van Gieson $(\times 24)$.

\section{Discussion}

Papilliferous tumours, such as those described in the present communication, may occur on any of the heart valves, usually on the ventricular surface of the semilunar valves, as in Case 1 , or on the atrial surface of the atrio-ventricular valves (Raeburn, 1953). There is no special age or sex incidence (Bohrod, 1929). Most of the previously reported papilliferous tumours of the heart valves have been single. An exception to this was the case of multiple tumours of the pulmonary valve reported by Bohrod (1929).

The previously reported tumours of the heart valves have been uniform in structure. As in the present cases, they are usually papilliferous and pedunculated tumours, the villi of which consist of a core of dense fibrous tissue, often showing hyaline change, with surrounding myxomatous tissue. The latter is composed of loose, cellular tissue and a mucoid material demonstrated in the present and previously reported cases to be an acid mucopolysaccharide. Raeburn (1953) showed that the characteristic staining reactions of the mucinous substance were removed by hyaluronidase, suggesting that the acid mucopolysaccharide present is, or is closely related to, hyaluronic acid. The tumours are covered by flattened epithelium and contain no iron. Elastic tissue is present, characteristically in the pedicle, as disorganized masses (as in Case 2) suggesting that the trauma of valve movement has broken down pre-existing elastic fibrils. Well-defined elastic fibrils may also occur immediately under the cellular lining of the tumour.

Widely differing views as to the nature of this tumour are held. According to Hertzog (1936), Curtis (1871) thought that the tumours reported at that time were inflammatory in origin as there was evidence of preceding endocarditis. Koechlin (1908) thought that these polyps might be unusually large excrescences of Lambl, a view still held by many pathologists today.

One variety of congenital endocardial sclerosis recognized by Craig (1949) consists of lesions, confined to the heart valves, which have a very similar histological appearance to that of the papilliferous tumours which form the subject of this paper. It has long been considered that such tumours may be neoplastic (Debove, 1873). They are similar to new growths occurring in the chambers of the heart, particularly around the margins of the fossa ovalis. A complex nomenclature has often 
been used to describe individual examples of what is basically one type of tumour. These names are based solely on the predominant tissues seen in the particular specimen reported. As early as 1929 Bohrod found that various authors had termed examples of these tumours myxoma, fibroma, fibro-angio-myxoma, and hæmangio-elasto-myxoma, and to this imposing list he added the term hæmangiofibroma.

Raeburn (1953) believes that tumours of this type have only a limited capacity for growth, which is not significantly greater than that of the surrounding normal tissues. He prefers to designate them hamartomas, qualifying this general term in a particular instance by prefixing the name of the predominant tissue present.

Most of the reported tumours have produced no symptoms and have been discovered incidentally at autopsy. Case 1 is a further example of this type. In Case 2, however, while the tumour was of identical structure, its peculiar position in relation to the ostium of the right coronary artery led to angina pectoris. This was presumably due to partial occlusion of the ostium from time to time by the pedunculated polyp.

\section{SUMmaRY}

Two papilliferous tumours of the semilunar valves are described. One occurred on the pulmonary valve of a man aged 57 years and gave rise to no symptoms. The other grew on the anterior cusp of the aortic valve of a woman aged 45 years. This partially filled the anterior aortic sinus, close to the ostium of the right coronary artery, and was associated with angina pectoris during life.

\section{REFERENCES}

Bohrod, M. G. (1929). Arch. Path., 8, 68.

Craig, J. M. (1949). Bull. int. Ass. med. Mus., 30, 15.

Curtis, M. B. (1871). Arch. Physiol. norm. Path., 4, 262.

Debove, G. M. (1873). Bull. Soc. anat. Paris, 48, 247.

Hertzog, A. J. (1936). Arch. Path., 22, 222.

Koechlin, E. (1908). Frankfurt Z. Path., 2, 295.

Margarey, F. R. (1949). J. Path. Bact., 61, 203.

Raeburn, C. (1953). J. Path. Bact., 65, 371. 